\title{
UMA OU VÁRIAS GEOGRAFIAS? *
}

\section{Ana Fani Alessandri Carlos}

\section{RESUMÉ}

Ce texte propose de penser l'unité de la geographie en tant qu'une partie du processus général de la connaissance et ainsi qu'une façon d'explication de la realité humaine.

La geographie elle même peut être analysée a partir de la preocupation avec la spacialization des relations sociales qu'on peut saisir dans la domaine de la production et reproduction de l'espace geographique.

A elaboração do tema do Painel segue, inicialmente, uma contradição nos termos que nos leva pensar na existência de mais de uma Geografia.

Inicialmente podemos nos perguntar se realmente podemos considerar uma Geografia para o ensino e outra para a pesquisa.

Muitos, com certeza, acreditam na existência de uma Geografia Física e de uma Geografia Humana. A própria prática da Geografia nos tem conduzido para a existência de pelo menos uma Geografia Física que se subdivide em Geomorfologia(s), Climatologia(s), Pedologia, etc. - e uma Geografia Humana subdividida em outras tantas: Geografia Urbana, Geografia da População, Geografia da Indústria, etc.

Esta contradição do tema, ou de seu entendimento, nos encaminha para a discussão inicial, da unidade da Geografia. E evidente que esta discussão tem como pano de fundo o processo de produção no mundo capitalista, onde o processo de trabalho, vinculado ao desenvolvimento das forças produtivas da sociedade, conduz a um aprofundamento da divisão do trabalho que não ocorre apenas no processo produtivo mas também no campo da ciência, criando uma série infindável de divisões e subdivisões que tem ocasionado, em muitos casos, a perda da perspectiva da unidade da ciência.
A noção de ciência se vincula a idéia de totalidade e a realidade àquela de totalidade concreta, portanto, como um todo estruturado que se autocria em seu processo constante de reprodução e a ciência, enquanto sua forma de expressão, se fundamentaria no dinamismo. A justificativa de uma ciência unitária repousaria, necessariamente, na idéia da mais profunda unidade da realidade objetiva.

Karel Kosik ${ }^{1}$ chama atenção para o fato de que a toalidade concreta é o princípio metodológico da investigação dialética da realidade social que antes de tudo significa que cada fenômeno só poderá ser apreendido como momento do todo.

Partindo-se do pressuposto de que a realidade concreta é um produto da história e esta é concebida como um processo de humanização da humanidade, a partir das relações que o homem mantém com a natureza, a ciência como representação do mundo real, aparece como histórica e social.

Enquanto produto social a realidade não está pronta e acabada, portanto, não está dada, impressa de forma inevitável na conciência humana, mas em cada momento é um produto histórico da humanidade. Desta feita o conhecimento da realidade histórica é um processo de apropriação teórica, isto é crítica, de interpretação e avaliação dos fenômenos e "o pensamento teórico de qualquer época, incluindo por conseqüente a nossa, é produto histórico que reveste formas muito distintas e assume, portanto, conteúdo muito distinto também, segundo as diferentes épocas" 2

$\left(^{*}\right)$ - Apresentado no Encontro de Geografos de Fortaleza, da Associação dos Geografos Brasileiros - AGB, em maio de 1987, no Painel: A geografia que se ensina e a geografia que se trabalha.

(1)-Dialética do Concreto, p. 40.

(2)-F. Engels. El auti, Dühring, p. 54. 
Partindo-se da realidade enquanto totalidade concreta, do indivíduo enquanto sujeito da história e do conhecimento como um processo em realização concomitante ao próprio processo histórico, caberia repensar a Geografia num outro contexto.

A Geografia coloca-se junto aos outros ramos do conhecimento como forma de explicação da realidade concreta. É a reprodução, ao nível da ciência, das relações de trabalho no campo da produção material e social.

A responsabilidade social do geógrafo reside na apreensão dos fatos reais, concretos, ultrapassando-se o nível da aparência (que possibilita a criação de fetiches) e elvando-se, a partir do real - através da elaboração de categorias - ao desvendamento do mundo fenomênico. O movimento de desvendamento do aparente dá-se na relação dialética entre fenômeno e essência.

A nosso ver a Geografia se coloca como um ramo do conhecimento que tem no seu centro de preocupação a análise da realidade através da espacialização das relações sociais manifestas na produção e apropriação do espaço geográfico. Ao contrário de acreditar que a Geografia seja a base da história mundial, mas um produto dela, de um determinado momento histórico peculiar a um estágio do desenvolvimento das forças produtivas, a Geografia surge como produto do processo de desenvolvimento que é cumulativo e crítico, que se reproduz enquanto ramo do conhecimento a partir das relações entre o novo e o velho o que implica em repensar constantemente a Geografia e as bases na qual esta sendo produzida, a partir da constatação do movimento real dos fenômenos.

Dentro dessa perspectiva, a Geografia teria um papel importante no processo de explicação da realidade o que implica um modo de pensar, fazer e ensinar a própria Geografia.

Ora, fica evidente em vários autores como Claval, Lacoste, Santos, entre outros que a Geografia não tem respondido as questôes que emergem do real.

"A Geografia brasileira a partir de meados da década de 70 vem passando por um processo de transformação quanto ao modo de entender e/ou analisar os fenômenos de sua alçada. Referimo-nos especificamente às questões relativas à concepção da Geografia, de seu papel enquanto ramo do conhecimento, seu poder explicativo e analítico e, finalmente, a questão da prática a partir ou através da geografia. A nova tendência surge com a preocupação de tornar a Geografia uma ciência analítica a partir da superação das descrições regionais e da reflxão sobre o seu objeto de estudo. Assim as discussões sobre o espaço geográfico ganham nova dimenão". ${ }^{3}$

O homem, enquanto ser social é o sujeito que produz o espaço e não elemento dele e o espaço, longe de ser organizado, é produto da ação humana, meio e condição da reprodução da vida. Nesse sentido o espaço não é humano porque o homem o habita, mas porque o produz à sua imagem e semelhança no processo de reprodução da humanidade.

O modo de fazer e/ou trabalhar a Geografia decorre dos pontos mencionados anteriormente além de colocar-nos a questão da responsabilidade social do geógrafo e do seu papel na sociedade atual. O modo de fazer a Geografia vincula-se estreitamente ao modo de pensá-la. A Geografia deve interpretar o espaço como fato histórico e a espacialidade das relações sociais colocam em relevo o fato de que o papel do espaço não pode ser minimizado nem reduzido ao palco da ação humana direcionando o interesse dos geógrafos para além da análise das formas.

Lacoste alerta para o fato de que nos nossos dias, a abundância dos discursos que tratam o reordenamento do território, em termos de harmonia, de busca de melhores equilíbrios serve apenas para mascarar as medidas que permitem às empresas, sobretudo as mais poderosas, aumentar seus lucros. É preciso ter claro que o reordenamento do território não visa apenas maximizar o lucro, mas também organizar estrategicamente o espaço econômico, social e político de modo que o aparelho do estado esteja à altura de esmagar os movimentos populares. ${ }^{4}$

Santos ${ }^{5}$ atenta para o fato de que a Geografia tradicional é incapaz de interpretar o dinamismo so-

(3) - A.F.A. Carlos. A (re)produção do espaço urbano. p. 12.

(4) - A geografia serve antes de mais nada, para fazer a guerra.

(5) - A responsabilidade social dos geografos. 
cial e atingir a verdadeira interpretação da realidade, além de não apontar para o futuro.

A nosso ver o caminho para uma Geografia comprometida e voltada para os anseios e necessidades da sociedade, esta na discussão do papel do homem na análise geográfica não enquanto homem habitante (Le Lannou) ou a sociedade tratada como coletividade humana (Brunhes) mas o homem enquanto sojeito, ser social e histórico que produz o mundo e a si mesmo, pertencente a uma sociedade de classes baseada em relação de dominação - subordinação. Nesse contexto o homem deixa de ser o agente geográfico de primeira ordem capaz de elaborar meios e ambientes, no dizer de Choley, para ser o sujeito da história produtor de sua humanidade e do espaço geográfico. Dentro desta perspectiva o espaço deixa de ser o palco da atividade humana, (La Blache) para ser o produto, a condição e o meio da reprodução da vida. Esta dimensão da análise geográfica, a partir do desvendamento da espacialidade das relações sociais, permite-nos, enquanto geógrafos, através do nosso trabalho - pensar o futuro.

A Geografia, nessa perspectiva, ultrapassa o nível empírico para atingir, via elaboração teórica, a representação explicitamente reproduzida da realidade estudada, enquanto produto da reflexão e do método a partir de um entendimento das causas e das leis das relações gerais. Assim, o trabalho intelectual peocupado com a explicação e/ou interpretação do zundo não produz sua transformação, mas é um passo importante na desmistificação das representações que permeiam a vida cotidiana.

Este novo modo de pensar e fazer a Geografia inplica, necessariamente, em transformações no modo de ensiná-la e conseqüentemente no processo constante de reprodução do professor a partir do deseavolvimento ininterrupto da ciência geografica.
A sala de aula é o locus onde se estabelece uma relação social e o ensino deixa de ser o ato de ingestão pura e simples de fatos sem importância (da Geografia tida como saber inútil) mas um processo reflexivo de elaboração do pensamento crítico. Coloca-se como fundamental - para nós, professores de Geografia - questionar o papel da Escola e da Universidade enquanto locus da reprodução das relações capitalistas de produção, aquela do saber "imposto, decorado, vomitado".

"O ensino deve ser exercido de modo livre para que o aprendizado permita a livre atuação da personalidade do ser humano e a tomada de consciência da realidade concreta em que vivem os homens e das contradições que dela emergem" 6

Paulo Freire ${ }^{7}$ coloca a idéia de que não há Educação fora das sociedades humanas e homens no vazio, portanto, é necessário pensar no tipo de sociedade em que vivemos, para poder apresentar respostas aos seus desafios o que implicaria numa opção: entre uma educação para a "domesticação" para a alimentação que produz o "homem-coisa" ou a educação para a "liberdade" para o homem-sujeito.

Uma Geografia comprometida com a sociedade e com as desmistificações dos fetiches ou uma Geografia alienada, representante do status quo. É o nosso desafio.

Recebido para publicação em 26/01/88.

(6) - A.F.A. Carlos. O ensino da geografia.

(7) - P. Freire. Educação como prática de liberdade. 